\title{
A fast-cooling mode for blue series furnaces
}

\author{
Christopher Goodway ${ }^{\mathrm{a}, *}$, Paul McIntyre ${ }^{\mathrm{a}}$, Adam Sears ${ }^{\mathrm{a}}$, Nadir Belkhier ${ }^{\mathrm{b}}$, Graham Burgess ${ }^{\mathrm{a}}$, \\ Oleg Kirichek ${ }^{\mathrm{a}}$, Eddy Lelièvre-Berna ${ }^{\mathrm{b}}$, Frédéric Marchal ${ }^{\mathrm{b}}$, Sébastien Turc ${ }^{\mathrm{b}}$ and Steven Wakefield ${ }^{\mathrm{a}}$ \\ a ISIS Neutron Facility, RAL, Didcot, Oxfordshire, OX11 OQX, U.K. \\ E-mails: chris.goodway@stfc.ac.uk,paul.mcintyre@stfc.ac.uk,adam.sears@stfc.ac.uk, \\ graham.burgess@stfc.ac.uk, oleg.kirichek@stfc.ac.uk, steven.wakefield@stfc.ac.uk \\ ${ }^{\mathrm{b}}$ Institut Laue-Langevin, 71 Avenue des Martyrs, 38042 Grenoble Cédex 9, France \\ E-mails: belkhier@ill.eu,lelievre@ill.eu,marchal@ill.eu,turc@ill.eu
}

\begin{abstract}
Blue series top-loading furnaces are regularly used at neutron facilities to carry out experiments at up to $1700^{\circ} \mathrm{C}$. The sample temperature is controlled using the indirect resistance heating method which consists in placing the sample inside a radiating cylindrical heater made from vanadium or niobium into which a current of up to 180 A circulates. To prevent the oxydation and deterioration of the heated elements, the sample, the heater and the heat shields are in a secondary vacuum which limits very much the cooling rate. We present an automated fast-cooling technique which reduces the cool-down time by a factor of 4 to 5 without impacting the lifetime of the heated elements. This method is now routinely used at the ILL and ISIS facilities and reduces very much beam time losses.
\end{abstract}

Keywords: Neutron scattering, sample environment, high temperature

\section{Introduction}

According to annual reports of the Institut Laue-Langevin (ILL), the ILL-type furnace, also known as the blue series, appeared in the mid-1980s after the importance of high temperatures at ILL was proven by 83 experiments requiring a furnace in 1980 (664 days). In 1975, several furnaces had been built and a lot of requests for help from users justified the creation of the "Furnace" group inside the "Sample Environment" department. The first successful ILL experiment performed at elevated temperature is certainly the measurement of the structure factor of liquid rubidium up to $1100^{\circ} \mathrm{C}$ and 200 bar [3].

In 1980, Raymond Serve launched an ILL furnace project based on Pierre Aldebert's design whom research works were pursued by a British team of scientists $[1,2]$. This furnace featured a double concentric resistor system and a very practical top-mounted electrical supply. The furnace reached $2500^{\circ} \mathrm{C}$ in 1981 and $2600^{\circ} \mathrm{C}$ in its third version in 1985 , even though, according to ILL annual reports [5], anything over $2000^{\circ} \mathrm{C}$ was strictly for specialists. Raymond Serve and Pierre Andant, followed by Paul Martin from 1990, devoted themselves to the production of a line of standard furnaces, schematically represented in Fig. 1, which were not only cheaper but much easier to maintain than the record-breaking furnaces. This was the blue series - a name that seemed to emerge in 1984.

In the late 1980s, Pierre Andant innovated with a monolithic resistor using point-welded $50 \mu \mathrm{m}$ niobium foils. In 1993, following the requests of other facilities, the production of the blue series handed over to the company AS Scientific Ltd (U.K.). Nowadays, these furnaces are still used at the ILL, the ISIS Facility (UK), the Paul Scherrer Institute (PSI, Switzerland) and many other neutron facilities worldwide.

The weakness of these furnaces is the impossibility to break the vacuum at temperatures above 100 or $150^{\circ} \mathrm{C}$ to prevent the oxydation and deterioration of the heating elements and heat shields made from vanadium or niobium. The samples are therefore cooled down in vacuum, which takes long times as shown in Fig. 2. This leads to beam

\footnotetext{
* Corresponding author. E-mail: chris.goodway@stfc.ac.uk.
} 


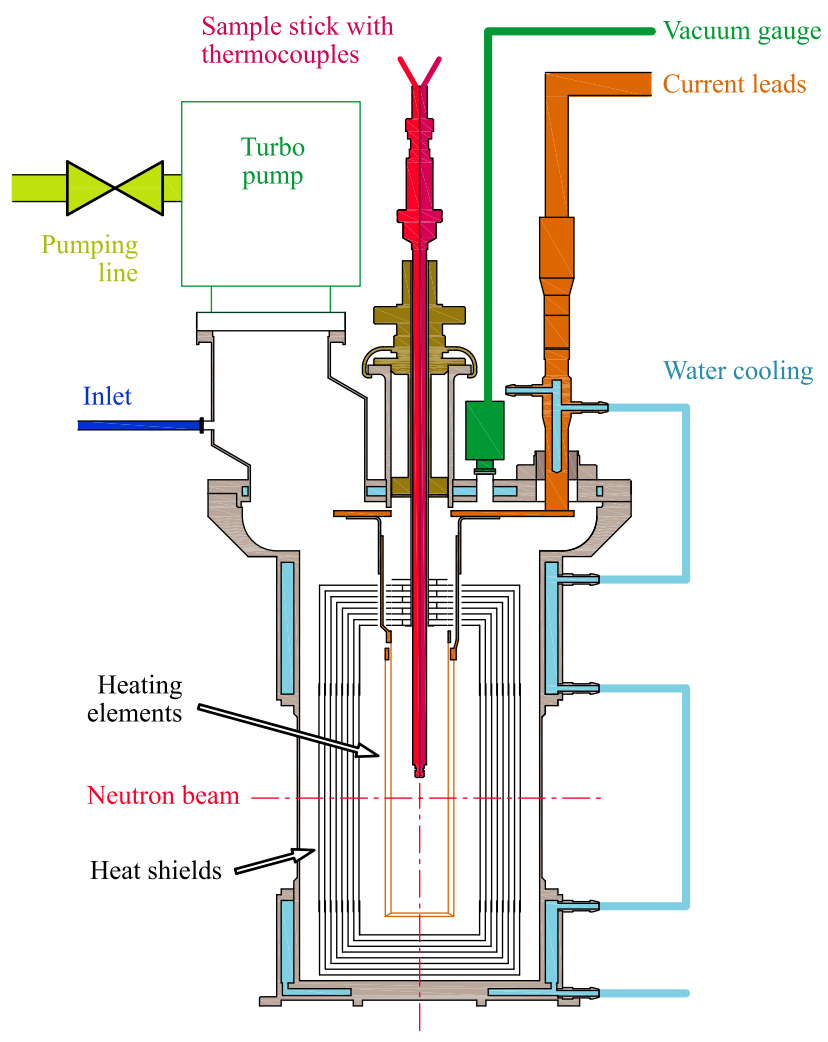

Fig. 1. Schematic representation of the blue series furnaces used at many neutron facilities. The temperature of the sample placed at the bottom of the stick is measured with thermocouples. The heating elements consist of a double concentric resistor made from 40 and $50 \mu \mathrm{m}$ vanadium and niobium foils respectively. It is surrounded by heat shields made from the same foils. The body and the current leads of the furnace are water cooled.

time losses which became unacceptable since the impressive progress made with neutron guides, neutron optics and detectors. For example, today, the time required to cool a sample down from $1000^{\circ} \mathrm{C}$ is about half the time required to perform a standard measurement on the time-of-flight spectrometer IN5 [4].

At ISIS, as shown in Fig. 2, exchange gas is introduced from $150^{\circ} \mathrm{C}$ to speed up the sample cooling and the team has experienced this process for more than 15 years. Following discussions held with ILL colleagues, the ISIS team has tested the injection of gas at higher starting temperatures, compared the cooling efficiencies of argon, helium and nitrogen in identical conditions, compared the efficiency of different injectors (top or bottom of the vacuum vessel), and finally determined the optimum flow rate (cost of gas vs cool down time). The fast-cooling mode developed at ISIS for long-tail furnaces has then been adapted to short-tail furnaces by the ILL team. Both teams have then automated the technique to ease users life and reduce beam time losses.

\section{Using exchange gas}

Without introducing exchange gas, the sample reaches a temperature of $100^{\circ} \mathrm{C}$ after approximately 6 hours. At ISIS, the team uses to back fill the vacuum chamber with helium gas from $150^{\circ} \mathrm{C}$ until the relief valve lifts. Injecting exchange gas when the temperature reaches $150^{\circ} \mathrm{C}$ reduces the cool-down time by almost 2 hours without taking the risk to deteriorate the heating elements and the heat shields. After the introduction of the exchange gas, the temperature of the body of the furnace goes up but it is only of about $5^{\circ} \mathrm{C}$. 


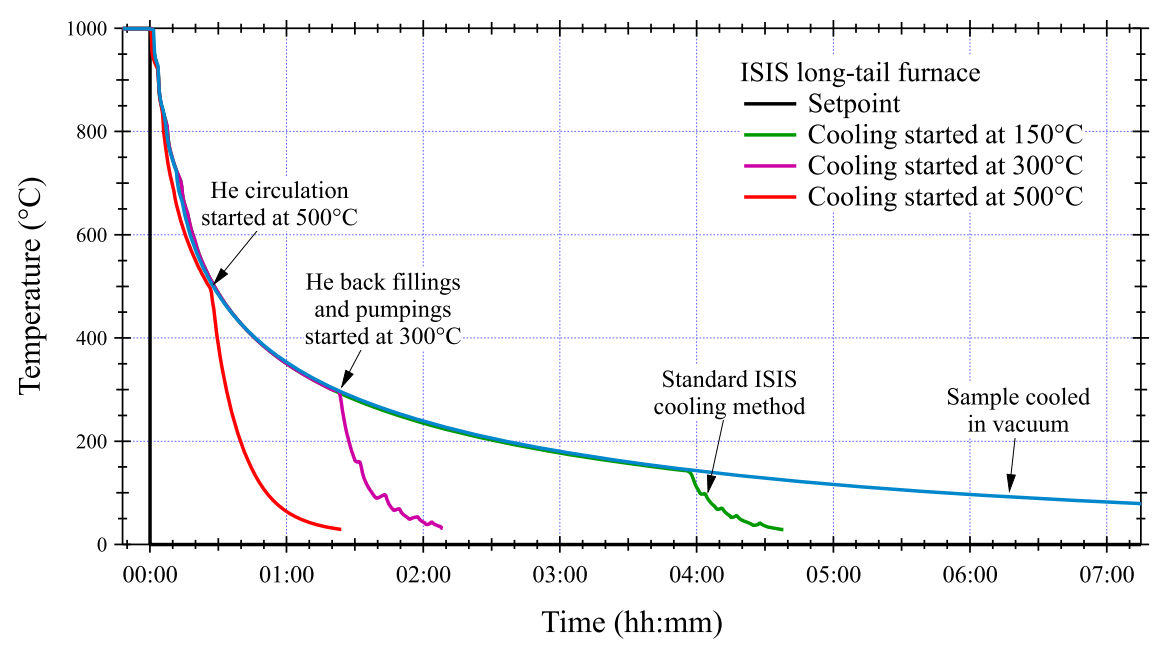

Fig. 2. Sample temperature variation after exchange gas introduction at 150,300 and $500^{\circ} \mathrm{C}$.

From this experience, the ISIS team tried to start introducing the gas at higher temperatures in a long-tail furnace. The tests, performed with a sample stabilised beforehand at $1000^{\circ} \mathrm{C}$, consisted in back filling the vacuum chamber and pumping it again once the temperature has dropped, and repeat this process until the temperature reaches $30^{\circ} \mathrm{C}$. This method leads to oscillations of the temperature as can be seen on Fig. 2 when the gas was introduced at 150 and $300^{\circ} \mathrm{C}$.

The curve obtained by starting injecting gas at $500^{\circ} \mathrm{C}$ was obtained by circulating the gas continuously with a flowmeter at a rate of $4 \mathrm{l} / \mathrm{min}$. This technique is a little faster and prevents too much heating of the vacuum chamber made from aluminium windows. The introduction of exchange gas at $500^{\circ} \mathrm{C}$ reduces by a factor 5 the cool-down time to reach $100^{\circ} \mathrm{C}$ : from 4 hours $45 \mathrm{~min}$ to only $45 \mathrm{~min}$. This limit of $500^{\circ} \mathrm{C}$ has been determined by measuring the temperature of the body of the furnace which reaches $\approx 100^{\circ} \mathrm{C}$. Indeed, higher temperatures must be avoided to reduce the risk of burns and avoid a deformation of the vacuum chamber made of aluminium.

The same tests were then conducted with other inert gases and the results are summarised in Fig. 3. As expected, helium clearly provides the best cooling rates, up to two times quicker than argon. It can be noted that this result does not depend whether the gas is injected at the bottom or top of the vacuum vessel.

\section{Optimum flow-rate of helium}

\subsection{Long-tail furnaces}

In order to further reduce beam time losses and prevent repeated heating of the body of the long-tail furnaces, the ISIS team has performed a series of cooling tests with a continuous flow instead of a single or repeated introduction of helium. The results, presented in Fig. 4, were obtained with helium flowed at 10, 5, 3, 2, 1 and $0.51 / \mathrm{min}$ using a standard flowmeter. Clearly, the optimum cooling rate is obtained above $21 / \mathrm{min}$. The gain in time is of only a few minutes but the temperature of the body of the furnace stays at acceptable temperatures, of the order of $40^{\circ} \mathrm{C}$.

\subsection{Short-tail furnaces}

The furnaces used at the ILL are slightly different than those used at ISIS. They have a smaller beam window and are closed at the bottom with an aluminium alloy flange which is easier to cool down. The mass to cool is therefore less important and the heat exchange is more efficient. In normal operation, the sample cools down to $100^{\circ} \mathrm{C}$ in about 2 hours 30 min compared to 4 hours at ISIS. 


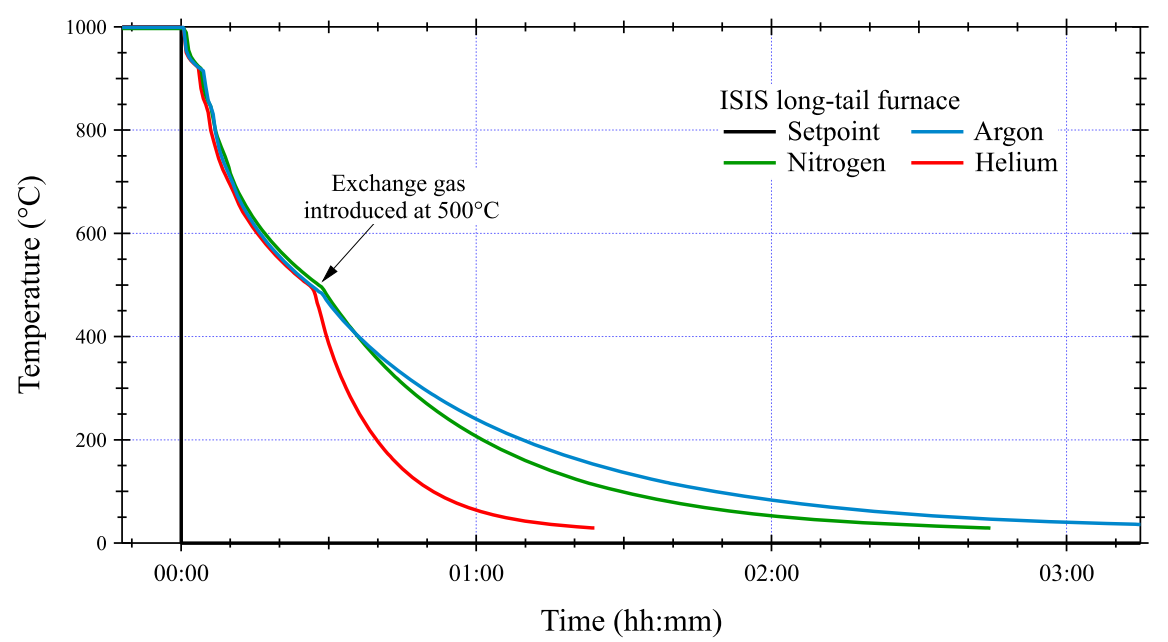

Fig. 3. Sample temperature variation after the introduction of argon, helium or nitrogen at $500^{\circ} \mathrm{C}$. As expected, a greater cooling rate is obtained with helium and the cool-down time to $100^{\circ} \mathrm{C}$ is reduced by almost 1 hour compared with argon.

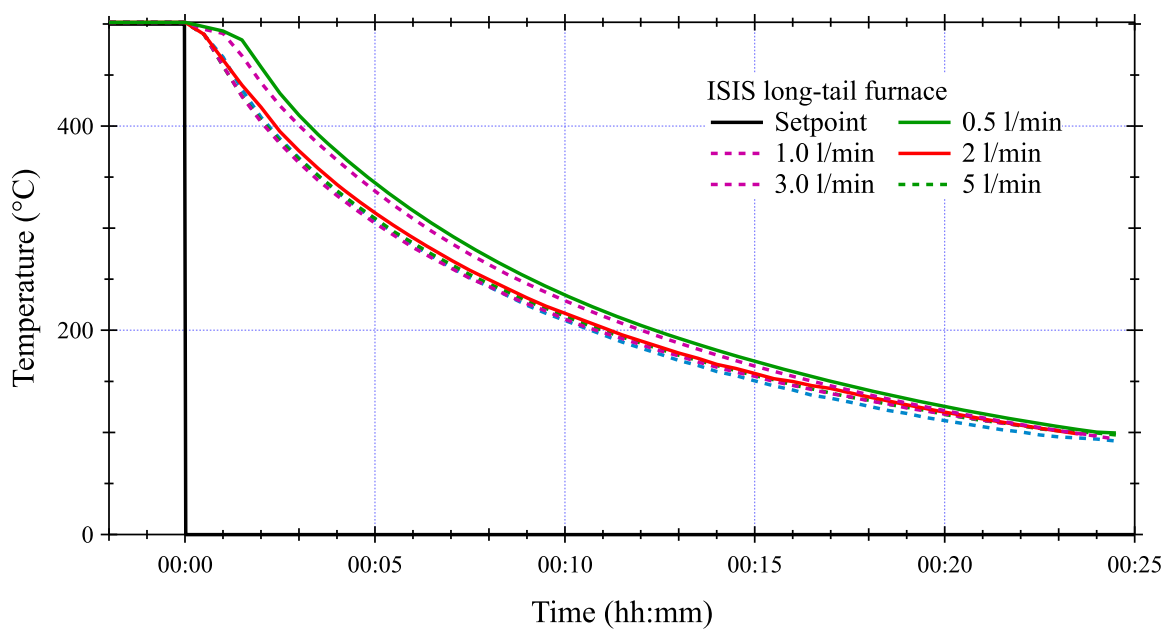

Fig. 4. Sample temperature variations observed when circulating helium from $500^{\circ} \mathrm{C}$ at different flow-rates. The cooling rate of the sample is marginally affected but the temperature of the body of the furnace, measured punctually, decreases sensibly from almost 100 to $40^{\circ} \mathrm{C}$ for a flow-rate of $21 / \mathrm{min}$.

Tests conducted at the ILL with the above parameters determined at ISIS also lead to very good results. A gain factor of 4 was obtained by flowing He exchange gas at $21 / \mathrm{min}$ starting from $500^{\circ} \mathrm{C}$ down to $100^{\circ} \mathrm{C}$. However, tests performed while decreasing the flow-rate to reduce the helium consumption also lead to similar results and it was finally concluded that an injection of $75 \mathrm{ml}$ of exchange gas is enough to reach the gain factor of 4 shown in Fig. 5.

\section{Automation of the fast-cooling mode}

Because some of us were expecting a reduction of the lifetime of the heating elements and heat shields of the furnaces, a manual setup has been adapted to all furnaces at ISIS and adopted in the experimental programs. 


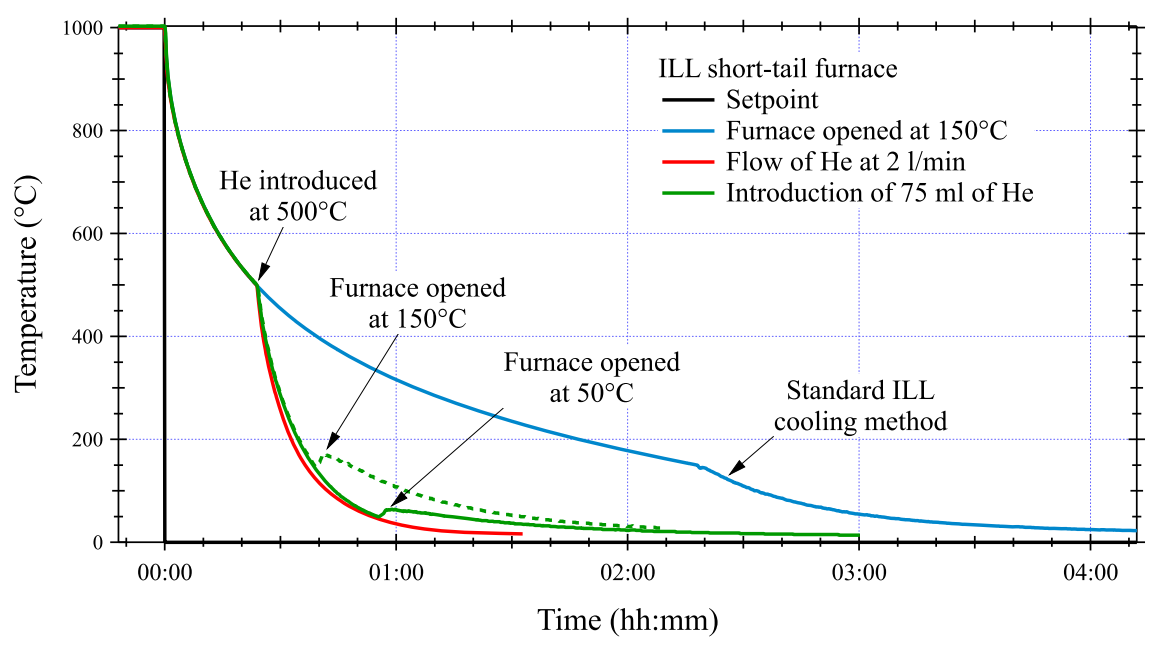

Fig. 5. Sample temperature variations observed for a short-tail furnace when circulating helium from $500^{\circ} \mathrm{C}$ at different flow-rates or when injecting only $75 \mathrm{ml}$ of $\mathrm{He}$. The dashed green line is obtained when the furnace is opened at a temperature of $150^{\circ} \mathrm{C}$ and the continuous green line when it is opened at $50^{\circ} \mathrm{C}$. Whichever fast-cool mode is used, the cool-down time to reach $100^{\circ} \mathrm{C}$ is always the same and four times shorter.

Records have been kept to identify if any change to the lifetime of the elements were shortened due to the rapid cooling. This has been conducted for almost a year and no shortening of the operational life has been observed.

We have therefore decided that the final system would be automated so that the new cooling process becomes an easy task or even a transparent task for the visiting scientists. The ISIS team has developed an electronics controlling the evacuation of the vessel, the heating of the sample and the regulation of the flow of helium. The components controlled by a PLC (Programmable Logic Controllers) are presented in Fig. 6. From the sample temperature reading, the pressure in the vacuum vessel and the user setpoint, the PLC decides what to do. It prepares the heating by pumping the vacuum vessel to a sufficient level before starting the turbo pump. Once the required pressure is reached, it launches the regulation loop and enables the heating. When the user requests a cooling, the PLC reduces the heating power, stops the turbo pump and closes the vacuum solenoid valve. When the sample temperature reaches $500^{\circ} \mathrm{C}$, after having checked that the heating power is off, it starts circulating helium in the furnace at a fixed flow-rate of $21 / \mathrm{min}$ until the temperature drops to $80^{\circ} \mathrm{C}$.

For ILL short-tail furnaces, the implementation of the fast-cool mode only requires a buffer and a set of valves allowing to inject $75 \mathrm{ml}$ of helium when the temperature becomes lower than $500^{\circ} \mathrm{C}$. This has been done by adding a fast-mode option to the PLC of the existing power racks. Users can enable or not this mode remotely from the instrument controller software.

\section{Conclusion}

We have presented a simple technique for reducing the cool-down times of blue series furnaces by a factor 4 to 5 . The technique consists in flowing or injecting a predefined quantity of helium gas from $500^{\circ} \mathrm{C}$. This fastcooling mode is fully automated with programmable logic controllers and can be remotely enabled or disabled. The upgraded furnaces and power racks are available at both the ILL and the ISIS facilities.

In 2018, 72 high-temperature experiments have been carried out at ISIS (181 days in total). Thanks to the fast cooling furnace system, over 42 days of neutron beam time have been saved, leading to an increase in efficiency of 23\%. This is vital as new neutron guides, optics and detectors enable fast data collection. This will also be essential for new facilities such as the European Spallation Source. 


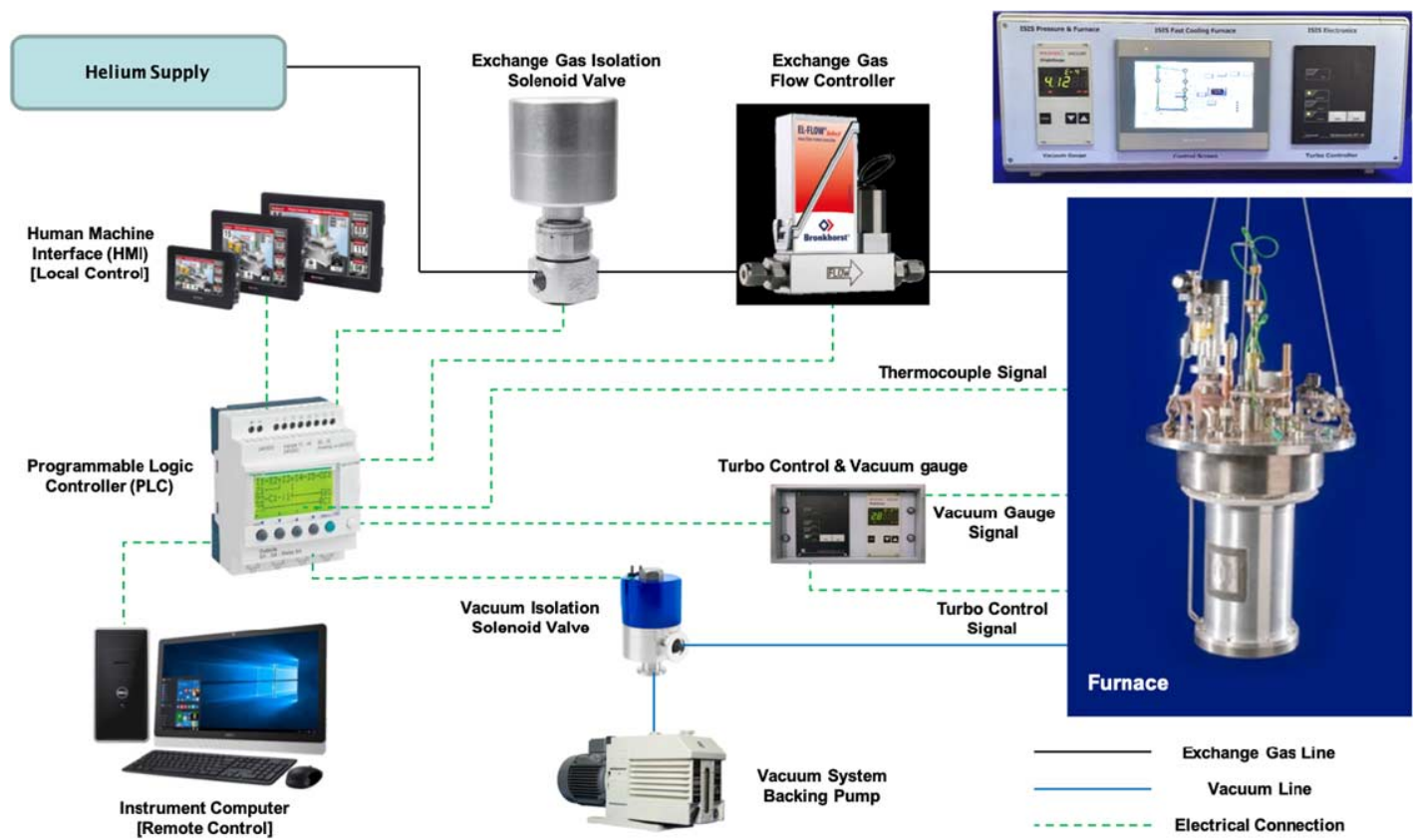

Fig. 6. Diagram of the components driven by a programmable logic controller to implement automatically the fast-cool mode on long-tail furnaces. A photo of the produced controller is shown at the top right, above a photo of a long-tail furnace.

\section{Acknowledgements}

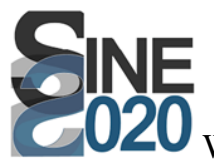

We thank very much colleagues from EU neutron facilities for the fruitful discussions held during this project and in particular M. Bartkowiak (PSI) and J. Peters (FRM II). This work was performed within the World class Science and Innovation with Neutrons in Europe 2020 ("SINE2020") project, funded by the European Commission, Grant Agreement no. 654000.

\section{References}

[1] P. Aldebert, Etude par diffraction et diffusion quasiélastic des neutrons de la mobilité anionique présentée à haute temperature par des oxydes réfractaires: Application à l'albumine et aux formes de haute temperature de la zircone et des sesquioxides de terres rares, $\left(\mathrm{La}_{2} \mathrm{O}_{3}\right.$ et $\mathrm{Nd}_{2} \mathrm{O}_{3}$ ), PhD thesis, Université Paul Sabatier de Toulouse, 1980.

[2] P. Aldebert, Neutron and X-ray experiments at high temperature, Revue de Physique Appliquée 19 (1984), 649-662. doi:10.1051/rphysap: 01984001909064900.

[3] R. Block, J.B. Suck, W. Gläser, W. Freyland and F. Hensel, Measurement of the structure factor of liquid rubidium by neutron diffraction up to $1400 \mathrm{~K}$ and 200 bar, Berichte der Bunsengesellschaft für physikalische Chemie 80(8) (1976), 718-721. doi:10.1002/bbpc.19760800811.

[4] J. Ollivier and H. Mutka, IN5 cold neutron time-of-flight spectrometer, prepared to tackle single crystal spectroscopy, Journal of the Physical Society of Japan 80(Suppl.B) (2011), 003. doi:10.1143/JPSJS.80SB.SB003.

[5] R. Serve, Annual Report (1983). 